\title{
Decreased density of GABA-A receptors in the left sensorimotor cortex in akinetic catatonia: investigation of in vivo benzodiazepine receptor binding
}

Georg Northoff, Reiner Steinke, Christian Czcervenka, Reiner Krause, Sven Ulrich, Peter Danos, Dieter Kropf, HansJürgen Otto, Bernhard Bogerts

\begin{abstract}
Objectives-Catatonia is a psychomotor syndrome with concomittant akinesia and anxiety which both respond almost immediately to benzodiazepines such as lorazepam. The benzodiazepine receptor distribution was therefore investigated in akinetic catatonia with single photon emission tomography (SPECT) using iodine-123-iomazenil ( ${ }^{123}$ I Iomazenil).
\end{abstract}

Methods-Ten akinetic catatonic patients, 10 psychiatric controls (similar age, sex, medication, and underlying psychiatric diagnosis but without catatonic syndrome), and 20 healthy controls were investigated with SPECT 2 hours after injection of ${ }^{123}$ I Iomazenil. To exclude potential effects of cerebral perfusion (r-CBF) r-CBF was additionally investigated with Tc-99mECD SPECT.

Results-Catatonic patients showed significantly lower iomazenil binding and altered right-left relations in the left sensorimotor cortex compared with psychiatric $(p<0.001)$ and healthy $(p<0.001)$ controls. In addition, there was significantly lower r-CBF in the right lower prefrontal and parietal cortex in catatonia whereas in the left sensorimotor cortex no differences in $\mathbf{r}-\mathrm{CBF}$ between groups were found. Catatonic motor and affective symptoms showed significant correlations $(p<0.05)$ with benzodiazepine binding in the left sensorimotor cortex as well as with right parietal $\mathbf{r}-\mathrm{CBF}$.

Conclusions-Reduced iomazenil binding suggests decreased density of GABA-A receptors in the left sensorimotor cortex in akinetic catatonia. In addition to reduced GABA-A receptor density in the left sensorimotor cortex the parietal cortex seems to be involved in pathophysiology of catatonic symptoms. It is concluded that, considering results from correlation analyses, both emotional and motor symptoms in catatonia seem to be closely related to left sensorimotor and right parietal alterations.

(F Neurol Neurosurg Psychiatry 1999;67:445-450)

Keywords: catatonia; GABA-A receptors; motor cortex; parietal cortex
Catatonia is a psychomotor syndrome which can be characterised by concomittant motor and emotional abnormalities. ${ }^{12}$ Patients show complete akinesia and intense and uncontrollable anxieties. ${ }^{34}$ Several clinical studies have shown the therapeutic efficiacy of benzoiazepines. ${ }^{4-7}$ Lorazepam, a benzodiazepine, leads to potentiation of inhibition mediated by GABA-A receptors and alterations in density of GABA-A receptors in cortical motor areas may thus be assumed in akinetic catatonia.

The GABA-A receptors have never been studied in akinetic catatonia. We therefore investigated akinetic catatonic patients with single photon emission computed tomography (SPECT) using iodine-123-labelled iomazenil $\left({ }^{123}\right.$ I Iomazenil) as a radioligand that selectively binds with high affinity to the benzodiazepine subunit of the GABA-A receptor complex in the human brain. Clinical studies in healthy volunteers have shown that it has a high brain uptake, relatively slow washout of radioactivity, a long half life, and appropriate regional distribution. $^{89}$ To exclude effects of cerebral perfusion on iomazenil binding and distribution we additionally investigated regional cerebral blood flow ( $\mathrm{r}-\mathrm{CBF}$ ) with Tc-99m ECD in the same subjects immediately after I-123-Iomazenil SPECT.

\section{Methods}

CATATONIC PATIENTS

We investigated 10 catatonic patients (six women, four men; mean age: 41.6 (SD 5.3) years; mean illness duration: 8.6 (SD 2.3) years; mean number of admissions to hospital: 3.5 (SD 0.9)) from psychiatric clinics Magdeburg, Haldensleben, and Blankenburg (incidence, calculated in relation to all incoming patients: $2.6 \%$ ). No significant differences in psychopathological measurements and imaging results were found between neuroleptically treated ( $\mathrm{n}=4 ; 5-20 \mathrm{mg}$ haloperidol for 1.1 (SD $0.4)$ years) and neuroleptically naive $(n=6)$ catatonic patients. In addition, patients were pretreated with antidepressant drugs $(n=3$; 50-200 mg amitryptilin), lithium ( $n=2$; serum concentration: $0.9 \mathrm{mmol} / \mathrm{l}$ ), and carbamazepin $(\mathrm{n}=1$; serum concentration: $8 \mu \mathrm{g} / \mathrm{ml}$ ), patients did not receive any benzodiazepines in the 6 months before admission (measurement of serum concentration of lorazepam according to the method of Greenlatt et al. ${ }^{10}$ on days $0,1,4$, and 8). Patients with chronic neurological or other physical illness, alcohol or other 
substance misuse, hyperkinesias, or dyskinesias as assessed with the abnormal involuntary movement scale (AIMS), ${ }^{11}$ or neuroleptic induced movement disorders as assessed with the scale for extrapyramidal side effects (SEPS) $>3^{12}$ were excluded from the study.

Psychopathological assessment were made with the global assessment scale (GAS), ${ }^{13}$ the positive and negative symptom scale (PANS), ${ }^{14}$ the Hamilton anxiety scale (HAM-A), ${ }^{15}$ and the Hamilton depresson scale (HAM-D) ${ }^{16}$ on days 0,1 , and 8 . All patients were right handed according to the Edinburgh Inventory of handedness. ${ }^{17}$ Comorbid diagnoses were made according to DSM $\mathrm{IV}^{18}$ on discharge showing the following diagnosis: catatonic schizophrenia (295.20: $\mathrm{n}=3$ ); bipolar I disorder (296.04c: $\mathrm{n}=1)$; major depression (296.34c: $\mathrm{n}=1)$; bipolar I disorder (296.44c: $\mathrm{n}=2$ ); bipolar I disorder (296.54c: $n=3$ ).

Catatonic syndrome (number of catatonic episodes during illness: 3.0 (SD 0.8); days of catatonic symptoms during current episode: 14.5 (SD 5.8) days) was diagnosed according to criteria by Lohr and Wisniewski (three from 11 symptoms), ${ }^{19}$ Rosebush et al (four from 12 symptoms), ${ }^{5}$ the Bush-Francis catatonia rating scale (BFCRS), ${ }^{6}$ and the Northoff catatonia scale (NCS). ${ }^{20}{ }^{21}$ Catatonic symptoms had to be manifest for at least half an hour on the day of admission in the presence of both examiners (GN; PD) who rated the same patients successively within 1 hour on days 0,1 , and 8 . Only patients with akinetic (exclusion of hyperkinetic catatonia; see Northoff et $a l^{4}{ }^{7}$ ) catatonia and reponse to lorazepam (single intravenous doses of $2 \mathrm{mg}$ ) in the first 24 hours $^{4}$ were included. In the next days all patients received no benzodiazepines but antidepressant $(n=5)$ or neuroleptic drugs $(n=8)$ until SPECT investigation, which took place on day 8 .

\section{CONTROL GROUPS}

Two control groups were investigated: (1) an age and sex matched psychiatric control group (age: 40.8 (SD 4.9) years; all right handed) comprised patients with a similiar diagnosis, illness duration, exclusion criteria, and medication as catatonic patients but without catatonic syndrome. The medication and SPECT protocols were similar to the catatonic groups. (2) A healthy control group of 20 subjects (age: 40.1 (SD 6.2) years; all right handed) matched for age and sex. Subjects with a history of psychiatric, neurological, or serious physical illness, drug or alcohol misuse, or first degree relatives with major psychiatric or neurological disorders were excluded. Ethics permission was obtained from the ethics committee of the University of Magdeburg and the administration of radioactive substances advisory committee. Informed consent was obtained from all subjects.

IMAGING PROCEDURE AND DATA ANALYSIS Iomazenil was synthesised and labelled with ${ }^{123} \mathrm{I}$ at the Paul Scherrer Institute (Villingen, Switzerland) according to the method described by Beer et $a .^{22}$ SPECT was performed with a rotating gamma camera (Siemens, Diacam) with a low energy, high resolution collimator (FWHM: $7.5 \mathrm{~mm}$ at $10 \mathrm{~cm}$ depth). Subjects were positioned supine in a rigid, concave headrest of fixed height with respect to the gantry, and the imaging table was locked into position. Images were obtained at 64 projections in a $64 \times 64$ matrix acquisition (pixel size: $8 \mathrm{~mm}$ ) over $360^{\circ}, 40$ seconds for each projection (revolution time: 40 minutes). The acquired frames were corrected for the injected dose and for the individual distribution volume by normalising to $1.73 \mathrm{~m}$ body surface. The effective half life of iomazenil during SPECT acquisition was estimated by measuring the activity in a $60 \%$ isocontour at the start (mean of frame 1 to 3 during SPECT) and the remaining activity at the end of acquisition (last three planar images of the 64 projections).

$200 \mathrm{Mbq}{ }^{123} \mathrm{I}$ iomazenil were given as a slow intravenous injection administered to the subject in a dimly lit, quiet room. ${ }^{23}$ As $\mathrm{rCBF}$ has only minor effects on delayed images of iomazenil binding ${ }^{23}$ SPECT imaging started 120 minutes postinjection. To avoid circadian variablity, ${ }^{24}$ the SPECT scans for all subjects were obtained at the same time of day $( \pm 30$ minutes). Directly after finishing ${ }^{123}$ I iomazenil SPECT Tc-99m ECD was injected in the same subjects to measure regional cerebral blood flow excluding blood flow effects in iomazenil distribution and binding.

All subjects underwent MRI on a Siemens 1.5 Tesla system using the standard head coil. 10 contigous $\mathrm{T} 1$ weighted axial images (thickness: $4 \mathrm{~mm}$, gap size: 0.3 ) were acquired up to planes parallel to the AC-PC line and coregistered with SPECT within the Siemens system to aid anatomical localisation and to exclude medium to severe brain atrophy, which was recently shown to significantly reduce $\mathrm{r}-\mathrm{CBF}$, RMRGlu values, and receptor density. ${ }^{25}$

Images were reconstructed by filtered back projection using a Butterworth filter of order 7 and a cut off frequency of $0.6 \mathrm{~cm}^{-1}$. Transverse slices were reoriented to the canthomeatal line using an external line source for landmarking. Slices in the other two orthogonal planes were then reangulated. The spatial resolution was 15 mm (full width half maximum (FWHM)) in the transaxial plane. Sixty four axial slices (exclusion of the most basal and the most dorsal slices), $1.66 \mathrm{~mm}$ thick, were reconstructed by using a filter with a cut off frequency of 0.6 cycles per pixel, and corrected for attenuation with a uniform linear attenuation correction coefficient of $0.12 \mathrm{~cm}^{-1}$. Regions of interest (ROIs) were determined using the anatomical atlases of Talairach and Tournoux ${ }^{26}$ and Kretschmann and Weinrich; ${ }^{27}$ corresponding ROIs of all slices were summed together and defined as follows: lower medial and lateral prefrontal cortex, lower frontal cortex, upper and lower temporal cortex, middle medial and lateral prefrontal cortex, middle frontal cortex, lower and upper parietal cortex, upper frontal cortex (which predominantly encomprises the sensorimotor cortex), and upper medial and lateral prefrontal cortex, each on the right and left hemisphere. All ROIs were larger than 
Table 1 Iomazenil binding (means (SD)) in catatonic patients, and psychiatric and healthy controls

\begin{tabular}{|c|c|c|c|c|c|c|}
\hline$R O I$ & $H E M$ & Ratio & $\begin{array}{l}\text { Catatonic patients } \\
(n=10)\end{array}$ & $\begin{array}{l}\text { Psychiatric controls } \\
(n=10)\end{array}$ & $\begin{array}{l}\text { Healthy controls } \\
(n=20)\end{array}$ & $p(V)$ \\
\hline Upper & $\mathrm{R}$ & $\mathrm{O}$ & $0.61(0.02) \mathrm{b}$ & $0.62(0.02)$ & $0.69(0.03)$ & 0.002 \\
\hline \multirow[t]{3}{*}{ Frontal } & & W & $0.93(0.02)$ & $0.94(0.05)$ & $0.95(0.04)$ & NS \\
\hline & $\mathrm{L}$ & $\mathrm{O}$ & $0.59(0.02) \mathrm{ab}$ & $0.63(0.02)$ & $0.65(0.02)$ & 0.001 \\
\hline & & $\mathrm{W}$ & $0.90(0.03) \mathrm{ab}$ & $0.95(0.03)$ & $0.96(0.03)$ & 0.002 \\
\hline $\begin{array}{l}\text { Upper } \\
\text { medial }\end{array}$ & $\mathrm{R}$ & $\mathrm{O}$ & $0.62(0.02) \mathrm{b}$ & $0.64(0.03)$ & $0.68(0.02)$ & 0.001 \\
\hline \multirow[t]{3}{*}{ Prefrontal } & & W & $0.94(0.04) \mathrm{b}$ & $0.98(0.05)$ & $1.01(0.03)$ & 0.005 \\
\hline & $\mathrm{L}$ & $\mathrm{O}$ & $0.60(0.02) \mathrm{b}$ & $0.63(0.02) \mathrm{c}$ & $0.68(0.05)$ & 0.001 \\
\hline & & W & $0.93(0.03) b$ & $0.95(0.04) \mathrm{c}$ & $1.00(0.03)$ & 0.001 \\
\hline Upper & $\mathrm{R}$ & $\mathrm{O}$ & $0.60(0.02) b$ & $0.62(0.02)$ & $0.66(0.03)$ & 0.001 \\
\hline Lateral & & W & $0.91(0.02) \mathrm{b}$ & $0.95(0.04)$ & $0.97(0.03)$ & 0.005 \\
\hline \multirow{2}{*}{ Prefrontal } & $\mathrm{L}$ & $\mathrm{O}$ & $0.60(0.02) \mathrm{b}$ & $0.61(0.03) \mathrm{c}$ & $0.66(0.03)$ & 0.001 \\
\hline & & W & $0.92(0.04) \mathrm{b}$ & $0.93(0.05)$ & $0.99(0.03)$ & 0.003 \\
\hline Upper & $\mathrm{R}$ & $\mathrm{O}$ & $0.64(0.02)$ & $0.65(0.03)$ & $0.65(0.03)$ & NS \\
\hline \multirow[t]{3}{*}{ Parietal } & & $\mathrm{W}$ & $0.98(0.04)$ & $0.99(0.05)$ & $0.99(0.04)$ & NS \\
\hline & $\mathrm{L}$ & $\mathrm{O}$ & $0.67(0.02)$ & $0.67(0.02)$ & $0.68(0.03)$ & NS \\
\hline & & W & $1.01(0.02$ & $1.01(0.05)$ & $1.01(0.02$ & NS \\
\hline Middle & $\mathrm{R}$ & $\mathrm{O}$ & $0.73(0.03)$ & $0.74(0.03)$ & $0.74(0.04)$ & NS \\
\hline Medial & & W & $0.99(0.02$ & $0.98(0.03)$ & $0.99(0.03)$ & NS \\
\hline \multirow[t]{2}{*}{ Prefrontal } & $\mathrm{L}$ & $\mathrm{O}$ & $0.74(0.02$ & $0.73(0.03)$ & $0.74(0.03)$ & NS \\
\hline & & W & $0.98(0.03)$ & $0.99(0.04)$ & $0.99(0.03)$ & NS \\
\hline Middle & $\mathrm{R}$ & $\mathrm{O}$ & $0.74(0.03)$ & $0.75(0.04)$ & $0.75(0.03)$ & NS \\
\hline Lateral & & W & $0.99(0.04)$ & $0.99(0.03)$ & $0.99(0.04)$ & NS \\
\hline \multirow[t]{2}{*}{ Prefrontal } & $\mathrm{L}$ & $\mathrm{O}$ & $0.75(0.04)$ & $0.75(0.03)$ & $0.76(0.03)$ & NS \\
\hline & & $\mathrm{W}$ & $0.88(0.04)$ & $0.98(0.03)$ & $0.99(0.04)$ & NS \\
\hline Lower & $\mathrm{R}$ & $\mathrm{O}$ & $0.74(0.03) \mathrm{b}$ & $0.74(0.02) \mathrm{c}$ & $0.78(0.02)$ & 0.001 \\
\hline Medial & & W & $1.14(0.02) \mathrm{b}$ & $1.13(0.03) \mathrm{c}$ & $1.20(0.02)$ & 0.001 \\
\hline \multirow[t]{2}{*}{ Prefrontal } & $\mathrm{L}$ & $\mathrm{O}$ & $0.73(0.02) \mathrm{b}$ & $0.73(0.02) \mathrm{c}$ & $0.77(0.02)$ & 0.04 \\
\hline & & $\mathrm{W}$ & $1.12(0.02) \mathrm{b}$ & $1.11(0.03) \mathrm{c}$ & $1.17(0.03)$ & 0.04 \\
\hline Lower & $\mathrm{R}$ & $\mathrm{O}$ & $0.74(0.03)$ & $0.74(0.04)$ & $0.75(0.02)$ & NS \\
\hline Lateral & & W & $0.99(0.04)$ & $0.98(0.05)$ & $0.99(0.03)$ & NS \\
\hline \multirow[t]{2}{*}{ Prefrontal } & $\mathrm{L}$ & $\mathrm{O}$ & $0.75(0.04)$ & $0.75(0.03)$ & $0.76(0.03)$ & NS \\
\hline & & W & $0.98(0.04)$ & $0.89(0.03)$ & $0.99(0.03)$ & NS \\
\hline Lower & $\mathrm{R}$ & $\mathrm{O}$ & $0.72(0.03)$ & $0.72(0.03)$ & $0.71(0.02)$ & NS \\
\hline \multirow[t]{3}{*}{ Parietal } & & W & $1.10(0.04)$ & $1.09(0.04)$ & $1.08(0.03)$ & NS \\
\hline & $\mathrm{L}$ & $\mathrm{O}$ & $0.74(0.02)$ & $0.74(0.02)$ & $0.74(0.03)$ & NS \\
\hline & & $\mathrm{W}$ & $1.14(0.03)$ & $1.13(0.02)$ & $1.12(0.02)$ & NS \\
\hline
\end{tabular}

Values are mean (SD). SROI=region of interest; HEM, R/L=right and left hemisphere; $\mathrm{O} / \mathrm{W}=$ occipital and whole brain ratio; $\mathrm{p}(\mathrm{V})=$ variance analysis; $\mathrm{a}, \mathrm{b}, \mathrm{c}=$ post hoc $t$ test $(\mathrm{p}<0.001)$ $\mathrm{a}=$ catatonic patients $<$ psychiatric controls; $\mathrm{b}=$ catatonic patients $<$ healthy controls; $\mathrm{c}=$ psychiatric controls $<$ healthy controls. dall's coefficients of correlation were found to be above 0.87 .

\section{STATISTICAL ANALYSIS}

Regional differences between groups were calculated using repeated measures analysis of variance (ANOVA) with one between subjects factor (groups) and one within subject factor (regions of interest) applying post hoc $t$ tests with Bonferroni corrections for multiple comparisons.

Right-left differences were calculated in three ways: (1) global right-left differences in a repeated measurement ANOVA with one between subject factor (group) and two within subjects factors (regions of interest, level (upper, middle, lower)); (2) right-left differences for each region of interest were analysed in univariate $t$ tests; (3) regions of interest were combined in a multivariate analysis for global right-left effects separately for each group and each level. A principal component test was used. $^{32}$

Relations between clinical/psychopathological data and iomazenil binding in the various regions of interest were calculated using parametric Pearson correlations.

\section{Results}

IOMAZENIL BINDING

Catatonic patients showed significantly lower iomazenil binding in the left upper frontal cortex (which predominantly encomprises the sensorimotor cortex) than psychiatric $(p<0.001)$ and healthy $(p<0.001)$ controls (table 1 and figure). Both catatonic patients and psychiatric controls showed significantly lower iomazenil binding in the right and left lower (and upper) prefrontal cortex $(p<0.001)$ than healthy controls (table 1). Iomazenil binding in parietal and temporal cortex ${ }^{33}$ and cerebellum did not differ significantly between groups.

Global right-left differences were significant at the lower and upper level in catatonia $(p=0.0001-0.004)$ and in the lower level in psychiatric controls $(p=0.0001)$ whereas there were no significant right-left differences in healthy controls. Regional right-left alterations were significant $(p<0.001)$ in the upper frontal cortex and lower medial and lateral prefrontal cortex in catatonia and in the lower medial and lateral prefrontal cortex (but not in the upper frontal cortex) in psychiatric controls. Unlike healthy controls, both catatonic patients and psychiatric controls showed right-left differences in the lower medial and lateral prefrontal cortex. This is further underlined by calculation of right-left differences in multivariate analysis. Significant effects of regions $(F=15.958 ; \quad \mathrm{df}=4.00 ; \quad \mathrm{p}=0.000), \quad$ levels $(F=12.519 ; \mathrm{df}=3.00 ; \mathrm{p}=0.000)$, and groups $(F=6.927 ; \mathrm{df}=3.00 ; \mathrm{p}=0.001)$ were found. The level by group interaction $(F=4.059 ; \mathrm{df}=6.00$; $\mathrm{p}=0.002)$ and the region by group interaction $(F=2.390 ; \mathrm{df}=8.00 ; \mathrm{p}=0.034)$ were significant.

PERFUSION (R-CBF)

Values that differed between groups are shown in table 2. $\mathrm{r}-\mathrm{CBF}$ in the left upper frontal 


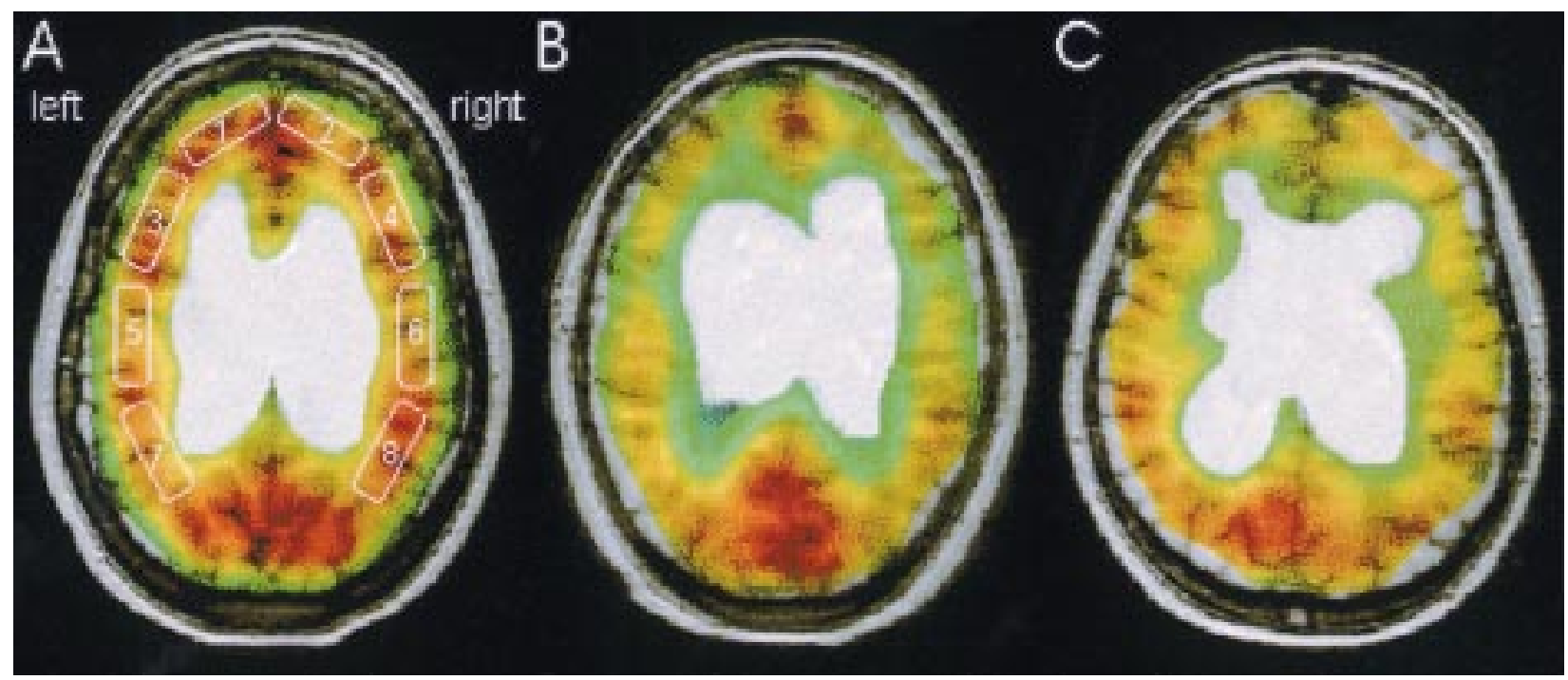

Iomazenil binding in a healthy control with regions of interest in upper level (A) and corresponding images in a catatonic patient (B) and a psychiatric control (C). Regions of interest: 1, 2=left and right upper medial prefrontal cortex; 3, 4=left and right upper lateral prefrontal cortex; 5, 6=left and right upper frontal cortex (including sensorimotor cortex; 7, 8=left and right upper parietal cortex.

cortex did not differ between groups. Catatonic patients showed significantly $(\mathrm{p}<0.001)$ lower $\mathrm{r}-\mathrm{CBF}$ in the right lower and middle prefrontal (medial and lateral) cortex as well as in the lower parietal cortex than psychiatric and healthy controls (table 2). In addition, catatonic patients showed significantly $(\mathrm{p}<0.001)$ right lower $\mathrm{r}-\mathrm{CBF}$ than healthy controls (table 2 ) in the left lower medial and lateral prefrontal cortex, left middle medial and lateral

Table 2 Mean $r$-CBF (means (SD)) in catatonic patients, and psychiatric and healthy controls

\begin{tabular}{|c|c|c|c|c|c|c|}
\hline$R O I$ & HEM & Ratio & $\begin{array}{l}\text { Catatonic } \\
\text { patients }(n=10)\end{array}$ & $\begin{array}{l}\text { Psychiatric } \\
\text { controls }(n=10)\end{array}$ & $\begin{array}{l}\text { Healthy controls } \\
(n=20)\end{array}$ & $p(V)$ \\
\hline Upper & $\mathrm{R}$ & $\mathrm{O}$ & $0.75(0.04)$ & $0.75(0.03)$ & $0.76(0.04)$ & NS \\
\hline \multirow[t]{3}{*}{ Frontal } & & W & $0.98(0.06)$ & $0.97(0.04)$ & $0.98(0.05)$ & NS \\
\hline & $\mathrm{L}$ & $\mathrm{O}$ & $0.74(0.05)$ & $0.74(0.04)$ & $0.75(0.04)$ & NS \\
\hline & & W & $0.990 .04)$ & $0.98(0.05)$ & $0.99(0.03)$ & NS \\
\hline $\begin{array}{l}\text { Upper } \\
\text { Medial }\end{array}$ & $\mathrm{R}$ & $\mathrm{O}$ & $0.73(0.03) b$ & $0.76(0.04)$ & $0.78(0.03)$ & 0.037 \\
\hline \multirow{3}{*}{ Prefrontal } & & W & $1.01(0.04)$ & $1.01(0.07)$ & $1.04(0.06)$ & NS \\
\hline & $\mathrm{L}$ & $\mathrm{O}$ & $0.74(0.04)$ & $0.74(0.05)$ & $0.75(0.03)$ & NS \\
\hline & & W & $0.98(0.03)$ & $0.98(0.04)$ & $0.99(0.04)$ & NS \\
\hline Upper & $\mathrm{R}$ & $\mathrm{O}$ & $0.72(0.04) b$ & $0.77(0.05)$ & $0.78(0.03)$ & 0.043 \\
\hline Lateral & & W & $1.02(0.05)$ & $1.03(0.06)$ & $1.05(0.04)$ & NS \\
\hline \multirow[t]{2}{*}{ Prefrontal } & $\mathrm{L}$ & $\mathrm{O}$ & $0.74(0.05)$ & $0.74(0.04)$ & $0.76(0.03)$ & NS \\
\hline & & W & $1.01(0.03)$ & $1.02(0.05)$ & $1.02(0.04)$ & NS \\
\hline Upper & $\mathrm{R}$ & $\mathrm{O}$ & $0.76(0.04)$ & $0.77(0.05)$ & $0.77(0.03)$ & NS \\
\hline \multirow[t]{3}{*}{ Parietal } & & W & $0.99(0.04)$ & $0.99(0.06)$ & $1.00(0.04)$ & NS \\
\hline & $\mathrm{L}$ & $\mathrm{O}$ & $0.74(0.03)$ & $0.75(0.04)$ & $0.75(0.03)$ & NS \\
\hline & & W & $1.01(0.04)$ & $1.02(0.03)$ & $1.02(0.04)$ & NS \\
\hline Middle & $\mathrm{R}$ & $\mathrm{O}$ & $0.65(0.06) \mathrm{ab}$ & $0.70(0.05) \mathrm{c}$ & $0.75(0.04)$ & 0.015 \\
\hline Medial & & W & $0.93(0.06) \mathrm{ab}$ & $1.01(0.07)$ & $1.02(0.06)$ & 0.003 \\
\hline \multirow[t]{2}{*}{ Prefrontal } & $\mathrm{L}$ & $\mathrm{O}$ & $0.69(0.07) \mathrm{b}$ & $0.71(0.04)$ & $0.76(0.03)$ & 0.023 \\
\hline & & W & $0.98(0.08)$ & $1.02(0.07)$ & $1.03(0.05)$ & NS \\
\hline Middle & $\mathrm{R}$ & $\mathrm{O}$ & $0.69(0.07) \mathrm{ab}$ & $0.73(0.05) \mathrm{c}$ & $0.77(0.05)$ & 0.027 \\
\hline Lateral & & W & $0.98(0.06) \mathrm{b}$ & $1.00(0.06)$ & $1.02(0.04)$ & 0.049 \\
\hline \multirow{2}{*}{ Prefrontal } & $\mathrm{L}$ & $\mathrm{O}$ & $0.72(0.07) \mathrm{b}$ & $0.73(0.05)$ & $0.78(0.04)$ & 0.044 \\
\hline & & W & $0.98(0.06)$ & $0.99(0.05)$ & $0.99(0.03)$ & NS \\
\hline Lower & $\mathrm{R}$ & $\mathrm{O}$ & $0.68(0.07) \mathrm{ab}$ & $0.74(0.06)$ & $0.76(0.04)$ & 0.009 \\
\hline Medial & & W & $0.96(0.07) \mathrm{ab}$ & $1.05(0.10$ & $1.04(0.05)$ & 0.015 \\
\hline \multirow[t]{2}{*}{ Prefrontal } & $\mathrm{L}$ & $\mathrm{O}$ & $0.71(0.06) \mathrm{b}$ & $0.74(0.06)$ & $0.78(0.03)$ & 0.04 \\
\hline & & W & $1.01(0.06)$ & $1.05(0.07)$ & $1.06(0.05)$ & NS \\
\hline Lower & $\mathrm{R}$ & $\mathrm{O}$ & $0.65(0.06) \mathrm{ab}$ & $0.72(0.07)$ & $0.74(0.06)$ & 0.02 \\
\hline Lateral & & W & $0.93(0.06) \mathrm{ab}$ & $1.02(0.09)$ & $1.01(0.08)$ & 0.04 \\
\hline \multirow[t]{2}{*}{ Prefrontal } & $\mathrm{L}$ & $\mathrm{O}$ & $0.66(0.06) \mathrm{b}$ & $0.72(0.07)$ & $0.75(0,06)$ & 0.002 \\
\hline & & W & $1.01(0.05)$ & $1.05(0.07)$ & $1.06(0.05)$ & NS \\
\hline Lower & $\mathrm{R}$ & $\mathrm{O}$ & $0.64(0.06) \mathrm{ab}$ & $0.72(0.06)$ & $0.72(0.05)$ & 0.014 \\
\hline \multirow[t]{3}{*}{ Parietal } & & W & $0.91(0.06) \mathrm{ab}$ & $1.02(0.09)$ & $1.00(0.04)$ & 0.008 \\
\hline & $\mathrm{L}$ & $\mathrm{O}$ & $0.66(0.06) \mathrm{b}$ & $0.73(0.07)$ & $0.74(0.06)$ & 0.022 \\
\hline & & W & $1.01(0.06)$ & $1.01(0.05)$ & $1.02(0.04)$ & NS \\
\hline
\end{tabular}

Abbreviations as for table 1 . prefrontal cortex, left lower parietal cortex, and right upper medial and lateral prefrontal cortex.

Global right-left differences were significant at the lower level in healthy controls $(\mathrm{p}=0.004-$ 0.012 ) and at all levels (upper, middle, lower) in catatonic patients $(p=0.000-0.023)$ whereas there were no significant right-left differences at any level in psychiatric controls. Catatonic patients showed significant $(\mathrm{p}<0.001)$ rightleft alterations in the lower and middle medial and lateral prefrontal cortex as well as in the lower parietal cortex whereas in healthy controls significant right-left differences were found only in the prefrontal but not in the parietal cortex. This is further underlined by calculation of right-left differences in multivariate analysis. Significant effects of regions $(F=12.44 ; \mathrm{df}=4.00 ; \mathrm{p}=0.000)$ and groups $(F=10.95 ; \mathrm{df}=2.43 ; \mathrm{p}=0.005)$ were shown. The group by region interaction was significant $(F=3.14 ; \mathrm{df}=8.88 ; \mathrm{p}=0.006)$.

\section{CORRELATIONS}

Iomazenil binding in the left upper frontal cortex correlated significantly positive $(r=0.662-$ $0.766 ; \mathrm{p}=0.010-0.049)$ with severity (NCSmot, NCSbeh, NCStot, Rosebush) and duration $(\mathrm{r}=0.699 ; \mathrm{p}=0.024)$ of catatonic (motor and behavioural) symptoms. Significant correlations were found between iomazenil binding in right lower lateral prefrontal cortex and severity (NCSmot) and duration of motor symptoms in catatonia $(r=0.711-0.784$; $\mathrm{p}=0.017-0.007)$. In addition, significant negative correlations $(r=-0.691 ; \mathrm{p}=0.033)$ were found between anxiety (HAM-A) and iomazenil binding in the left upper frontal cortex as well as between depressive (HAM-D) symptoms and iomazenil binding in the right lower lateral prefrontal cortex in catatonic patients $(r=-0.692 ; \mathrm{p}=0.027)$ but not in psychiatric controls.

By contrast significant negative correlations between affective symptoms (HAM-A, HAM-D) and iomazenil binding in the left 
lower prefrontal cortex $(r=-0.678-0.808$; $\mathrm{p}=0.031-0.005)$ were shown only in psychiatric controls but not in catatonic patients. Psychiatric controls did not show any significant correlations between psychopathological scores and iomazenil binding in the left upper frontal cortex.

Right lower parietal r-CBF correlated significantly negative with motor (NCSmot) $(r=-0.739, \mathrm{p}=0.020)$ and affective (NCSaff, HAM-D) $\quad(r=-0.716 / 0.725 ; \mathrm{p}=0.015 / 0.019)$ symptoms in catatonic patients. Psychiatric controls showed significantly negative correlations between $\mathrm{r}-\mathrm{CBF}$ in the right lower (medial and lateral) prefrontal cortex and depressive symptoms (HAM-D) $(r=-0.649$ $0.732 ; \mathrm{p}=0.003-0.001)$.

\section{Discussion}

The main findings in the present study are the following: (1) significantly lower iomazenil binding with significant right-left alterations in the left sensorimotor cortex in catatonia; (2) significantly reduced $\mathrm{r}-\mathrm{CBF}$ and significant right-left alterations in the right lower prefrontal and parietal cortex in catatonia; (3) significant relations of motor and affective symptoms in catatonia with left upper frontal and right lower prefrontal cortical iomazenil binding as well as with right lower parietal $\mathrm{r}-\mathrm{CBF}$.

Several studies showed immediate therapeutic effects of lorazepam, a GABA-A potentiator, in akinetic catatonia. ${ }^{5-7}$ We therefore assumed alterations in density of GABA-A receptors in cortical motor and premotor areas in pathophysiology of akinesia in catatonia. $^{24734}$ The present study showed reduced iomazenil binding and altered rightleft relations in the left sensorimotor cortex in akinetic catatonia suggesting a decrease in the density of GABA-A receptors in the primary motor cortex. This finding is further supported by the following observations: (1) no reduction of $\mathrm{r}-\mathrm{CBF}$ in the left sensorimotor cortex so that effects of $\mathrm{r}-\mathrm{CBF}$ on iomazenil binding are rather unlikely; (2) reversal of therapeutic effects of lorazepam on akinesia by GABA-A antagonists (for example, Ro 15-1788) with reoccurence of catatonic symptoms; $;^{35}$ (3) therapeutic efficiacy of electroconvulsive therapy in akinetic catatonia which, similarly to benzodiazepines, is sought to act via the GABA system; ${ }^{234}$ (4) injection of GABA-A receptor agonists (for example, muscimol) into the motor cortex in monkeys leads to catatonic-like alterations in movements (akinesia, posturing) which could be reversed by GABA-A antagonists (for example, biccuculline; ${ }^{36-38}$; (5) delayed (within 2-4 hours) therapeutic effects of amantadine in akinetic catatonia ${ }^{39}$ which, via blockade of excitatory NMDA-receptors, indirectly strengthens cortical inhibition.

In addition, we found an opposite relation of motor and affective symptoms in catatonia with left sensorimotor cortical iomazenil binding. Motor symptoms correlated positively whereas affective alterations showed negative correlations. Considering the positive correlation, therapeutic effects of lorazepam in catatonia seem rather paradoxical as increase of
GABA-ergic mediated inhibition should then go along with an increase of motor symptoms. However, affective catatonic symptoms showed an inverse correlation with sensorimotor and prefrontal cortical iomazenil binding so that lorazepam may modulate motor symptoms and GABA-ergic function in the motor cortex via affective and prefrontal GABA-ergic regulation. ${ }^{40}$ Such an assumption of a close pathophysiological relation between motor and affective symptoms in catatonia would be supported by the following observations: (1) significant correlations of affective and motor symptoms with both prefrontal and frontal cortical iomazenil binding in catatonia; (2) a close relation between emotions and movements in subjective experience of akinetic catatonic patients who, unlike parkinsonian patients, retrospectively report rather about intense and uncontrollable anxieties than about movement disturbances ${ }^{4}$; (3) lorazepam shows immediate therapeutic efficiacy only in catatonic patients with strong emotional alterations whereas those with less affective symptoms do not respond to lorazepam. ${ }^{4}$

Similarly to other studies ${ }^{41-43}$ we found deficits of $r-C B F$ in the right parietal cortex ${ }^{41-43}$ which, in addition, correlated significantly with catatonic motor and affective symptoms. The parietal cortex has been found to be involved in motor attention and preparation of movements ${ }^{44-46}$ both showing specific alterations in catatonia: (1) catatonic patients are not aware of movement disturbances whereas they are fully aware of emotional alterations ${ }^{4}$ which may be interpreted as a deficit in motor attention; (2) catatonic patients show deficits in the preparation of movements ${ }^{3}$; (3) observation of catatonic-like posturing in patients with isolated lesions in right parietal cortex ${ }^{47}$; $(4)$ significant impairment in visual-spatial functions, as measured with the visual-spatial object perception test, which is particuarly sensitive to right parietal cortical lesions, in catatonia. ${ }^{49}$

However, the exact pathophysiological relation of $\mathrm{r}-\mathrm{CBF}$ deficits in the right parietal and right prefrontal cortex with decreased iomazenil-binding in the left sensorimotor cortex remains unclear so that specific investigation of motor attention and preparation is necessary in catatonia.

1 Kahlbaum K. Die Katatonie oder das Spannungsirresein. Eine Form psychischer Krankheit. Berlin: Hirschwald Verlag, 1874 .

2 Northoff G. Katatonie. Einführung in die Phänomenologie, Klinik und Pathophysiologie eines psychomotorischen Syn-

3 Northoff G, Wenke J, Krill W, et al. Ball-experiments in 32 acute akinetic catatonic patients: deficits of internal initiation and generation of movements. Mov Disord 1995; 10:589-95.

4 Northoff G, Krill W, Eckert J, et al. Major differences in subjective experience of akinetic states in catatonic and parkinsonic patients. Cognitive Neuropsychiatry 1998;3: 161-78.

5 Rosebush P, Furlong B, Mazurek M. Catatonic syndrome in a general psychiatric inpatient population: frequency, clinical presentation and response to lorazepam. $\mathcal{F}$ Clin Psychiatry 1990;51:357-62.

6 Bush G, Fink M, Petrides G, et al. Catatonia. Rating scale and standardized examination. Acta Psychiatr Scand 1996:93:129-43.

7 Northoff G, Wenke J, Demisch L, et al. Catatonia: short-term response to lorazepam and dopaminergic metabolism. Psychopharmacology 1995;122:82-186. 
8 Woods SW, Seibyl JP, Goddard AW, et al. Dynamic SPECT imaging after injection of the benzodiazepine receptor try Res 1992;45:67-77.

9 Lassen NA. A reappraisal of the relative merits of SPET and PET in the quantitation of neuroreceptors: the advantage of a longer half-life. Eur F Nucl Med 1996;23:1-4.

10 Greenblatt D, Franke K, Shader R. Analysis of lorazepam and its glucuronide metabolite by electron-capture gasliquid chromatography. If Chromatography 1978;146:31120.

11 Guy W. Assessment manual for psychopharmacology. Washington, DC: $1976: 76-338$

12 Simpson GM, Angus JWS. A rating scale for extrapyramidal side effects. Acta Psychiatr Scand 1970;212:11-19.

13 Endicott J, Spitzer R, Flies J, et al. The global assessment scale. Arch Gen Psychiatry 1976;33:766-71.

14 Kay SR, Opler LA, Fiszbein A. Positive and negative syndrome scale (PANSS) rating manual. San Rafael, CA: Social and scale (PANSS) rating manual. San Raf.

15 Hamilton $M$. The assessment of anxiety states by rating. $B r$ 7 Med Psychol 1959;32:50-5.

16 Hamilton M. A rating scale for depression. $f$ Neurol Neurosurg Psychiatry 1960;23:56-62.

17 Oldfield RC. The assessment and analysis of handedness: the Edinborough inventory. Neuropsychologia 1971;9:97113.

18 American Psychiatric Association. Diagnostic manual of mental disorders. 4rd ed. Washinton, DC: American Psychiatric Press, 1994.

19 Lohr JB, Wisniewski AA. Movement disorders: a neuropsychiatric approach. New York: The Guilford Press, 1987.

20 Northoff G, Koch A, Wenke J, et al. Catatonia as a psychomotor disease: a rating scale, subtypes and extrapyramidal motor symptoms. Mov Disord 1999;14:404-416.

21 Gelenberg AJ. Criteria for the diagnosis of catatonia. $A m \mathcal{F}$ Psychiatry 1977;134:462-3.

22 Beer HF, Bläuenstein PA, Hasler PA, et al. In vitro and in vivo evaluation of iodine-123-Ro 16-0154: a new imaging vivo evaluation of iodine-123-Ro 16-0154: a new imaging agent for SPECT investigations of benzo

23 Bartenstein P, Ludolph A, Schober O, et al. Benzodiazepine receptors and cerebral blood flow in partial epilepsy. Eur $\mathscr{f}$ Nucl Med 1991:118:111-18.

24 Bartlett EJ, Brodie JD, Wolf AP, et al. Reproducibility of cerebral glucose metabolic measurements in resting human subjects. F Cereb Blood Flow Metab 1986;8:502-12.

25 Sabri O, Hellwig D, Kaiser HJ, et al. Effects of morphological changes on perfusion and metabolism in cerebral microangiopathy. Nucl Med 1995;34:50-6.

26 Talairach J, Touroux P. Atlas of stereotaxic anatomical correlations for gray and white matter. New York: Thieme Verlag, 1993.

27 Kretschmann HJ, Weinrich W. Clinical neuroanatomy and cranial diagnostic imaging. 2nd ed. New York: Thieme Verlag, 1991.

28 Kojima A, Matsumoto M, Takahashi M. Effect of spatial resolution on SPECT quantification values. $7 \mathrm{Nucl} \mathrm{Med}$ 1989;30:508-14.

29 Schröder J, Bubeck B, Demisch S, et al. Benzodiazepine receptor distribution and diazepam binding in schizophrenia: an exploratory study. Psychiatry Res 1997; 68:125-31.
30 Joseph AB, Anderson WA, O'Leary DH. Brainstem and vermis atrophy in catatonia. Am $\mathcal{F}$ Psychiatry 1985;142: vermis

31 Wilcox JA. Cerebellar atrophy and catatonia. Biol Psychiatry 1991;29:733-4.

32 Läuter J, Glimm E, Kropf S. New multivariate tests for data with an inherent structure. Biometrical fournal 1996;38:522

33 Onishi Y, Yonekura Y, Tanaka F, et al. Delayed image of iodine-123 iomazenil as a relative map of benzodiazepine receptor binding: the optimal scan time. Eur f Nucl Med 1996;23:1491-7.

34 Petrides G, Divadeenam K, Bush G, et al. Synergism of orazepam and electroconvulsive therapy in the treatment of catatonia. Biol Psychiatry 1997;42:375-381.

35 Wetzel H, Heuser I, Benkert O. Stupor und affektiver Zustand: Besserung psychomotorischer Störung durch Lorazepam und Wiederkehr der Symptome nach der Gabe von Ro 15-1788. F Nerv Ment Dis 1987;175:4-6.

36 Hikosaka O, Tanaka M, Sakamoto M, et al. Deficits in manipulative behaviors induced by local injections of muscimol in the first somatosensory cortex of the conscious cimol in the first somatosensory cor
monkey. Brain Res 1985;325:375-80.

37 Kubota K. Motor cortical muscimol injection disrupts forelimb movement in freely moving monkeys. Neuroreport 1996;7:2379-84.

38 Kurata K, Hoffman D. Differential effects of muscimol microinjection into dorsal and ventral aspects of the premotor cortex of monkeys. F Neurophysiol 1994;71:115164.

39 Northoff G, Eckert J, Fritze J. Glutamatergic dysfunction in catatonia? Successful treatment of three acute akinetic catatonic patients with the NMDA antagonist amantadine. ₹ Neurol Neurosurg Psychiatry 1997;62:404-6.

40 Lane RD, Reiman EM, Ahern GL, et al. Neuroanatomical correlates of happiness, sadness, and disgust. Am F Psychiatry 1997;154:926-33.

41 Satoh K, Suzuki T, Narita M, et al. Regional cerebral blood flow in catatonic schizophrenia. Psychiatry Res 1993;50: 203-16.

42 Liddle PF. Volition and schizophrenia. In: A David, J Cutting, ed. The neuropsychology of schizophrenia. Hillsdale:

43 Galynker I, Weiss J, Ongseng F, et al. ECT treatment and cerebral perfusion in catatonia. F Nucl Med 1997;38:251-4.

44 Deiber MP, Ibanez V, Sadato N, et al. Cerebral structures in motor preparation in humans: A PET study. $\mathcal{F}$ Neurophysiol 1996;75:233-43.

45 Gitelmann D, Alpert N, Kosslyn S, et al. Functional imaging of human right hemispheric activation for exploratory movements. Ann Neurol 1996;39:174-9.

46 Jueptner M, Stephan KM, Frith CD, et al. Anatomy of motor learning. Frontal cortex and attention to action. $f$ Neurophysiology 1997;77:1313-24.

47 Fukutake T, Hirayama K, Komatsu T. Transient unilateral catalepsy and right parietal damage. Fpnese fournal of catalepsy and right paries
Psychiatry 1993;47:647-50.

48 Saver JL, Greenstein P, Ronthal M, et al. Asymmetric catalepsy after right hemispheric stroke. Mov Disord 1993;8:6973.

49 Northoff G, Nagel D, Danos P, et al. Impairment in visualspatial function in catatonia: a neuropsychological investigation. Schizophr Res 1999 (in press). 